\title{
Caregivers' use of, and attitudes towards, written asthma action plans in North-West Melbourne
}

\author{
C.A. Barton ${ }^{a}$, N.D. Sulaiman ${ }^{b, *}$, D.M. Clarke ${ }^{c}$, M.J. Abramson ${ }^{a}$ \\ a Department of Epidemiology and Preventive Medicine, Monash University, Melbourne, Australia \\ b Department of General Practice, The University of Melbourne, Broadmeadows Health Service, \\ 35 Johnstone St, Broadmeadows, Victoria 3047, Australia \\ c Department of Psychological Medicine, Monash University, Australia
}

Received 21 July 2004; accepted 31 October 2004

Summary We investigatéd the latlicudes of caregivels towrow written asthma

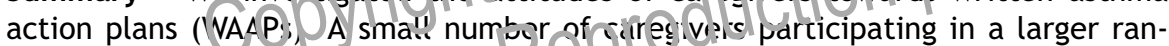
domised controlled trial (RCT) paricipat $=d$ in qualitative interviews. 'Ownership and use of WAAPs' and 'Schools and WAAPs' were the main themes to emerge. The new school year is an opportunity to review and update WAAPs.

(c) 2004 General Practice Airways Group. Published by Elsevier Ltd. All rights reserved.

\section{Introduction}

There has been little research into the attitudes of caregivers toward written asthma action plans (WAAPs). A recent Australian study reported that adults with asthma viewed action plans positively, but reinterpreted their plans from their own experiences with asthma [1]. Clearly, action plans are potentially of limited value if patients who possess them do not utilise them, or modify them extensively [2].

\footnotetext{
* Corresponding author. Tel.: +61 38344 4523; fax: +61393476136.

E-mail address: n.sulaiman@unimelb.edu.au (N.D. Sulaiman).
}

We have previously described the determinants of WAAP ownership in this group [3]. Here, we took a qualitative approach to investigate the use and attitudes toward written asthma action plans of parents caring for children with episodic asthma.

\section{Methods}

This qualitative study was nested within a larger RCT of asthma education delivered to General Practitioners (GPs) in Melbourne, Australia [3]. The University of Melbourne human research ethics committee granted ethical approval for the nested study. 
201 caregivers indicated that they would be interested in participating in a follow up study about asthma. To select a manageable, but rich data set, we randomised the list of caregivers; however, the final order in which they were approached was determined by purposeful sampling [4]. This involved assessing participants on a caseby-case basis by one of the authors (CB) for severity of asthma, with the small number of parents reporting moderate or severe asthma approached first. The remaining caregivers were then telephoned in the order in which they were initially randomised. Quota sampling [4] was used such that there were a minimum of ten participants from each of the intervention and control arms of the RCT, and at least ten participants who had a recent asthma exacerbation requiring assistance from a health professional (GP or Emergency Department).

Ten caregivers refused to participate due to time limitations $(n=1)$, the child's asthma not being severe enough $(n=1)$, or loss of interest $(n=8)$. A further six caregivers were unable to be contacted by telephone. Sampling continued until saturation of themes was reached [4]. Twenty-two interviews were completed. One interview of poor sound quality had to be discarded, leaving a final sample of twenty-one caregivers.

\section{Qualitative data colletticn}

Data collection involved a single, semi-structured in-depth interview with the primary caregiver. The interview lasted between 30 and $90 \mathrm{~min}$ and all but one of the interviews were conducted in the participants' homes.

\section{Data analysis}

Interviews were transcribed verbatim and analysed thematically for emergent themes. Preliminary coding guided revisions to the interview guide [5].

The software package QSR NVivo (Version 2.0) (Qualitative Solutions and Research International, Melbourne, 2002) was used for data management.

\section{Results}

\section{Description of participants}

The average age of the children was 7 years. Seven children reported moderately severe asthma (33\%), although just under half $(48 \%)$ reported an
Emergency Department attendance for asthma in the past three months. 13 children (62\%) had a WAAP and two children had a verbal action plan. Despite this, only six caregivers reported using their action plan at home. Most children (17 of 21) had a written action plan at their school, although only 12 of these were provided by a health professional and four children had no asthma action plan at school.

Two themes emerged from the qualitative interviews: 'use of written asthma action plans'; and 'schools (or crèches) and action plans'. Quotes from participants supporting these themes are presented in Table 1.

\section{Use of written asthma action plans}

Participants could be grouped into one of three categories based on their ownership and use of WAAPs. These were: caregivers who possessed and continued to use written instructions $(n=6)$; those who possessed instructions, but no longer used them or modified them $(n=7)$; and caregivers who did not have a WAAP $(n=8)$.

Caregivers vho bowinued to use their WAAPs repored inat written instructions were reassuring for them both as nanagers of asthma, and when their cofildren were under the care of someone el.je. Written instructions gave them greater confidence to adjust their children's medication as part of asthma management. However, some plans had not been updated despite new medications or regimens.

Caregivers who possessed written instructions but no longer used them felt that the WAAP was not relevant because 'they knew what to do', had 'familiarity with the plan', or because of 'knowing their child'. However, even these caregivers often found it useful to give the WAAP to school or to extended family.

Caregivers who did not possess a WAAP typically had not been offered a WAAP, even though some had asked their GP for a set of written instructions.

\section{Schools and asthma action plans}

Caregivers whose children had experienced a recent emergency attendance for asthma tended to provide schools with written instructions from a health care professional. Caregivers whose child had a co-morbid food allergy also did this. However, the group of caregivers who did not have a set of written instructions, and some who no longer used their WAAP, chose to write their own 
Table 1 Selected comments from caregivers about the asthma action plan.

Ownership and use of written asthma action plans

Participant 1116 "he's had this one since October, 2001, um, April 2002 (the GP) was going to try and reduce the Seretide but we haven't go that far, so, we're still on this until we can reduce the Seretide, so um. Oh he's on Singulair as well, so, but its not written on there.

Participant $\mathbf{2 7 2 5}$ "I know it off by heart. You know, its only there so if I needed to hand it to where ever JS is for someone else that's all, I mean I practically follow my own action plan which is around their action plan..."

Interviewer Do you find it (the written action plan) useful?

Participant 3035 "very... just to refresh, or you know to know that for sure that we're doing the right thing when you're giving him medication especially when things get worse, or come back to being better."

Schools and written asthma action plans

Participant 121 "I've still got the asthma action management plan. Because it has to be signed by my doctor and my doctor doesn't come back until the 20th which is um Thursday...."

Interviewer "Did your doctor draw up the plan or did you put it together?"

Participant 121 "we just basically worked it out ourselves."

Interviewer "Do you have a written action plan for asthma?"

Participant 1213 "yes. Its at school, we've given them a list of what to do if he has asthma, what to do if he has an allergic reaction, what he can eat, what he can't eat because the school provides meals..."

Interviewer "Did you have to give the crèche written instructions of what to do if she had an asthma attack?"

Participant 1229 "yeah I did. Yep hmmm."

Interviewer "Is that something your GP did for you?"

Participant 1229 " no I did it. Because actually, she told me last time I was there last week and she told me she was going to do a written plan for her...Although she's very good, I have to admit the doctor is very good but she's never given me anything in writing...",

Participant 1305 "The last one I wrote was last year, when he went on his grade 6 crmpins. When he goes away camping I have to write an action plan and give it to the teachers with his matratis, in a bag with his medication so the teachers know."

instructions and govel byse to the schobl, or provided no visitien ifistructions at al (t) fable 1).

\section{Discussion}

This study shows that the use of WAAPs by caregivers falls into three distinct categories: those who use them studiously; those who use them haphazardly and modify them as they see fit; and those who do not use them at all. Over half of the caregivers interviewed fell into the latter two categories.

Almost half the caregivers who possessed a WAAP modified their plan, or no longer used it. In order to reduce the likelihood of this outcome, WAAPs should be developed in collaboration with patients, and barriers to asthma management and solutions should be discussed [6]. Caregivers reported that the WAAP was used in a variety of settings. GPs should discuss with caregivers the settings in which the child may require a written set of instructions and adapt the plan as necessary. Future qualitative studies should determine if the level of patient involvement in developing a WAAP impacts on the use of the plan.
Supplying a WAAP to schools was an important issue. Caregivers without a WAAP, or those who no longer used them, often provided a self-written summary to the school. This raises the question of the accuracy of information provided to schools, and consequently raises the question of clinical liability if the child's asthma is mismanaged at school as a result. We would argue that parental instinct is not an adequate measure by which school staff should judge the time when a child needs urgent care. A standardised approach to providing information about asthma management at school would be valuable. School-specific WAAPs have now been made available to Victorian schools participating in the Asthma Friendly Schools program [7], and we look forward to the evaluation of this initiative.

The limitations of this study are the same for most qualitative studies. Since the sample is purposefully selected it may not be representative. However, by employing quotas we increased the diversity of individuals and their experiences. Furthermore, we continued sampling until saturation of themes had occurred.

The beginning of the school year provides an opportunity for clinicians to review asthma and to update the WAAP. A WAAP specifically 
for use in a school setting, and updated yearly by a health professional, could improve asthma management.

\section{Acknowledgements}

Christopher Barton was supported by scholarship from the National Health and Medical Research Council of Australia. We wish to thank Dr Rosalie Aroni for her assistance in development of the interview guide and study design, and Julie Attard for assistance with transcription of the taped interviews. We are grateful to the participants who gave their time so generously.

We would also like to thank the anonymous reviewers of this manuscript for their helpful and constructive comments.

\section{References}

[1] Douglass J, Aroni R, Goeman D, et al. A qualitative study of action plans for asthma. BMJ 2002;324:1003-8.

[2] Sawyer S. Action plans, self monitoring and adherence: changing behaviour to promote better self-management. MJA 2002;177(Suppl):S72-4.

[3] Sulaiman ND, Barton CA, Abramson MJ, et al. Factors associated with ownership and use of written asthma action plans in North-West Melbourne. Primary Care Respiratory Journal 2004;13(4):211-7.

[4] Polit DF, Hungler BP. Nursing Research: Principles and Methods. 5th Ed. USA: B Lippincort Co.; 1995.

[5] Strauss A, Corbin J. Basics of Qualitative Research. 2nd ed Ca.: Sage; 1998.

[6] Peterson-Sweeney K, McMullen A, Yoos HL, et al. Parental perceptions of their child's asthma: management and medication use. Journal of Pediatric Health Care 2003;17(3):118-25.

[7] School Asthma Action Plan. www.asthma.org.au/schoolsactionplans.htm.

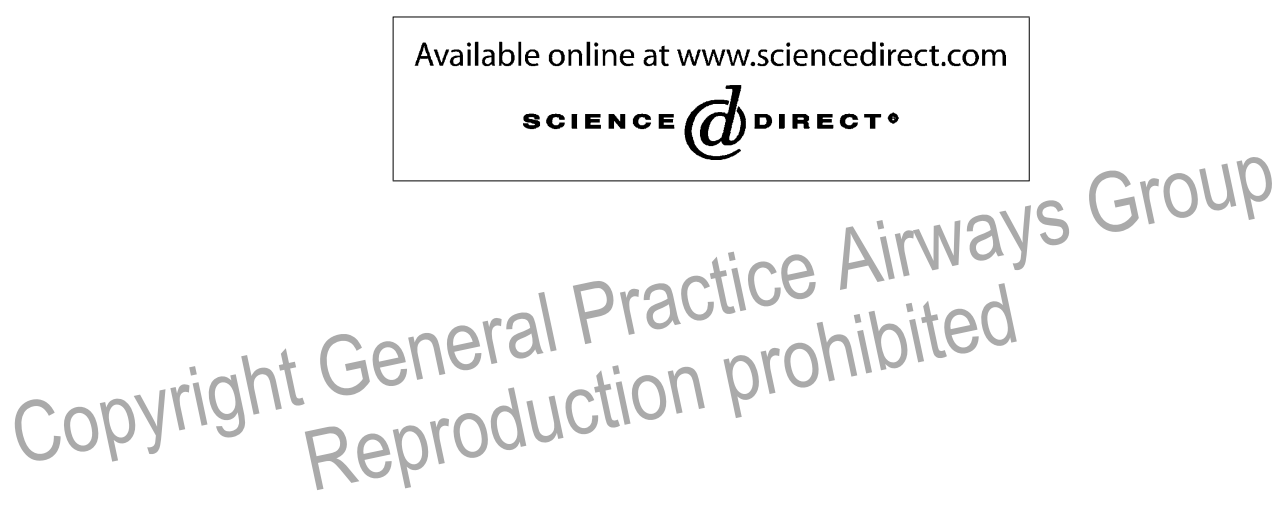

Available online at http://www.thepcrj.com 